\title{
TELRIC - the way towards competition? A European point of view
}

\author{
MORTEN FALCH*
}

Center for Tele-Information, Technical University of Denmark

\begin{abstract}
One of the most important issues in the debate on interconnect regulation has been use of forward looking costs for setting of interconnection charges. This debate has been ongoing within the EU as well as in US. This paper discusses the European experiences and in particular the Danish experiences with use of cost based interconnection charges, and their impact on competition in the telecom market.
\end{abstract}

\section{Introduction}

Setting of interconnection charges is the most important question for regulation of competition in telecom markets. The key issue has been how to establish a pricing mechanism that ensures both optimal competition and investment in network facilities. Following the US Supreme Court decision supporting the use of TELRIC for setting interconnection charges, it may be appropriate to assess the European experiences with a similar price setting regime.

This paper will discuss these experiences with regard to three aspects that all relate to the objections made by the incumbent carriers on the US telecom market:

(1) Does TELRIC induce competition?

(2) Does TELRIC provide a framework for fair and objective rate-setting?

(3) Is TELRIC unreasonably complicated?

In order to answer these questions from a European point of view we will look at the experiences from the telecom market in Denmark. Due to early liberalisation, the Danish telecom market is among the most competitive in Europe. The market was liberalised well ahead of the 1998 deadline set by the Commission, and Denmark was also among the first countries to demand the incumbent carrier to provide local loop unbundling.

First we describe the concept of Long Run Average Incremental Costs (LRAIC), on which the EU regulation of cost based interconnection charges is based, and compare it with TELRIC. Then we will describe how the regulatory framework for interconnection has developed and finally we analyse the impact on competition.

\footnotetext{
* Mailing address: Center for Tele-Information, build. 271.2, Technical University of Denmark, DK-2800 Lyngby, Denmark. E-mail address: falch@cti.dtu.dk.
} 


\section{TELRIC vs. LRAIC}

The European Commission recommends that the EU member countries introduce cost based interconnection charges based on LRAIC (CEC, 1997; CEC, 1998). At present, all EU countries as well as most of the Eastern European countries with the ambition to become full members of the EU, are in the process of introducing cost-based interconnection rates.

The purpose of using the LRAIC approach is to base the interconnection charges on what the cost of an interconnect product would be, if provided by the most efficient network operator and not on the current cost of production. This will enable new entrant operators to use existing network facilities without paying for possible inefficiencies of the incumbent operator in management, sub-optimal investments etc. In addition, new entrant operators should be stimulated to invest in alternative networks as soon as their businesses can support it. Finally the aim is to improve consensus among telecom-operators by including them in the process.

Therefore LRAIC is here defined as the forward-looking long run average costs of adding one increment to the network. The long run implies that all costs of all types of input can be included, including the costs of capital equipment. LRAIC includes all types of costs related to a certain increment not only the costs of adding one additional increment. Hence the concept of LRAIC is broader than LRIC which is defined as the marginal costs of adding or removing a certain increment of traffic. Moreover the Danish definition of LRAIC operates with very large increments such as 'all services in the access network' or 'all services in the core network'. All fixed costs related to either the core- or the access networks such as land, buildings or trenches are thus included in the costs of one of these two increments. Only costs shared by the access - and core networks are excluded (NTA, 2002: 3).

Like TELRIC, LRAIC assumes use of optimum technology given the existing location of wire-centers (the scorched network approach). The difference between Total Element Long-Run Incremental Cost (TELRIC) and LRAIC is that LRAIC does not include costs shared by more increments. However, the definition of very large increments limits the impact of this difference as most costs can be allocated either to the access- or the core network. ${ }^{1}$

\section{Principles for determination of interconnection charges on the Danish market}

The present goal for the Danish telecom policy was back in 1995 formulated as the ambition to be "best and cheapest through real competition". Competition on the Danish market was to be promoted through an early liberalisation combined with a rather strict competition regulation. The idea was for Denmark to be among the first countries in Europe to liberalise its telecom market, and thereby attract foreign investment in that market. A key issue was to ensure low interconnection charges in order to enable new entrants to compete with the incumbent operator TDC.

\footnotetext{
1 The difference between LRAIC and TELRIC is explained in detail in Intven (2000).
} 
By the adoption of a new telecom legislation in July 2000, it was decided that interconnection rates in the future should be based on LRAIC. The National Telecom Agency (NTA) therefore initiated the construction of a cost model for the Danish telecom network building on the LRAIC concept. This work is expected to be completed by the end of 2002.

The present principles for determination of interconnection charges were introduced in 1996, and are based on historical costs. The principle was to allow inclusion of the total extra costs related to provision of the service plus a reasonable margin. Five different elements were included in the costs: (1) Direct extra operating costs, (2) A proportion of the costs of new investments needed due to delivery of the interconnect service, (3) A proportion of depreciation and payment of interest for network facilities used for the service, (4) A proportion of the operating cost for these facilities and (5) An overhead of $12 \%$ of the total costs of (1)-(4).

The proportions of the costs in (2)-(4) are calculated on basis of the proportion of the traffic delivered through interconnection. However, if the dominant operator (i.e. TDC, the incumbent carrier) has a market share of more than $80 \%$, only $30 \%$ of the proportion of the operating costs must be included. This implies that the incumbent operator should bear a part of the interconnection costs until the new entrants have obtained a reasonable market share. In this way the monopolist is required to subsidise its competitors until some of them have established themselves on the Danish market.

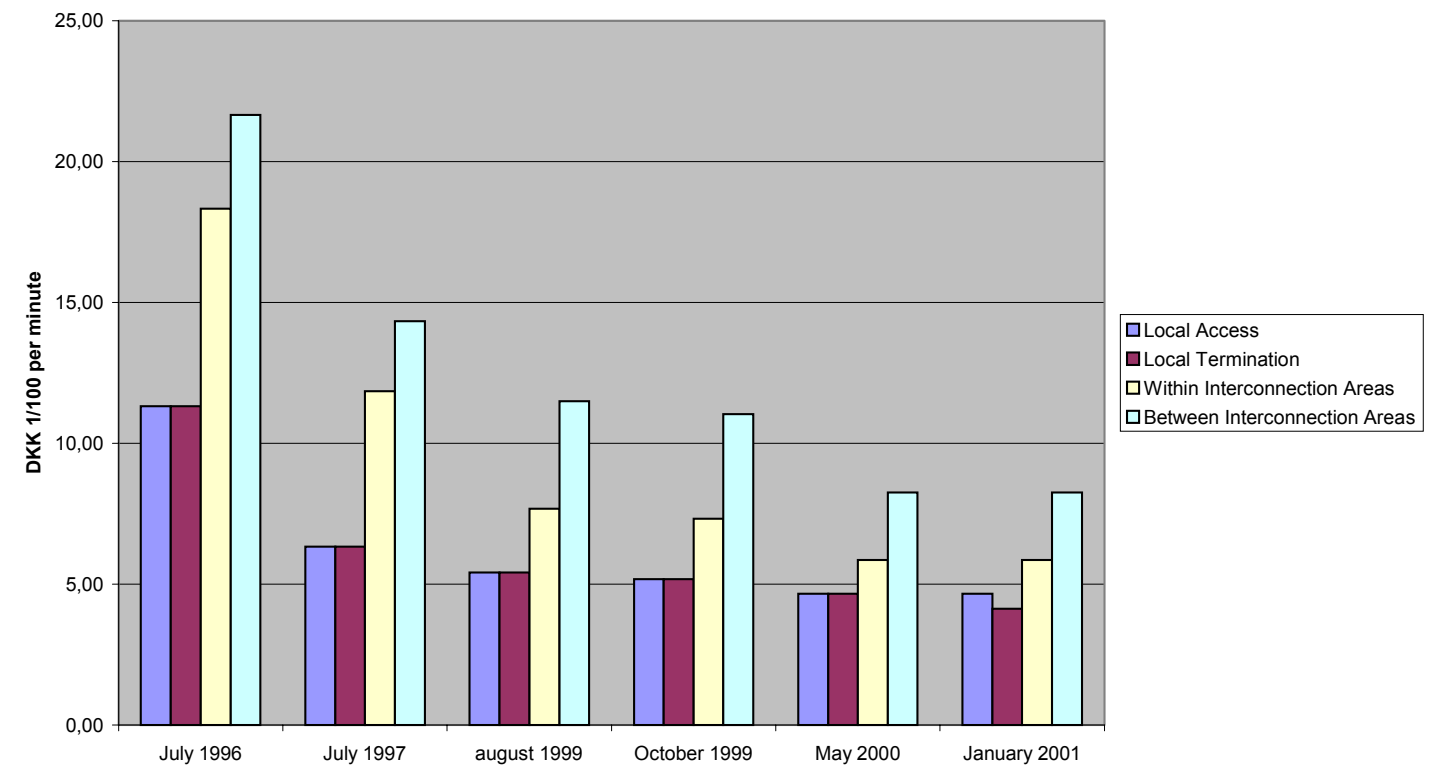

Note: 100 DKK = 12.7 USD. Source: National Telecom Agency: Status 2001 Annex A

Figure 1: Developments in interconnection prices during the period from mid 1996 to the beginning of 2001

The historical cost approach was in 1998 supplemented by a best practice clause, enabling the national telecom regulator to reduce interconnection charges to the 
international level for best practice, even if TDC was able to document that the actual costs are higher. The definition of best practice has been changed after several debates between the telecom agency, TDC and the new entrants. Currently best practice is defined as the average of the interconnection rates in the three countries with the lowest interconnection rates. It is also possible for the national telecom agency to reduce rates if they are lower in just one country, but in this case corrections for country specific conditions must be made beforehand. Although both the historical costs approach and the best practice clause are included in the legislation as ways for setting interconnection rates, it is the best practice clause that has been used to reduce the interconnection charges five times since July 1996 (see figure 1 above). This clause has ensured that Danish interconnection charges are always among the lowest in Europe.

\section{$4 \quad$ The LRAIC modelling process}

It was decided that both incumbent and new entrant operators should participate in the price setting. LRAIC models should be developed through a co-operation between three parties: The National Telecom Agency (NTA), operators with a strong market position obliged to deliver interconnect services at cost based prices (i.e., TDC), and operators who need to buy these services to complement their own network facilities (the new entrants). The new entrants have formed a common working group (the Bottom-up Working Group) which participates in the modelling work. This group includes among others Sonofon, Orange, Telia and Tele2. Although these companies can all be characterised as new entrants as well as net buyers of interconnect services, they also differ significantly with respect to interest and strategies. Sonofon and Orange are first of all mobile operators, while Tele 2 provides mainly fixed services. Telia is a new entrant in Denmark but an incumbent operator in Sweden, and the most ambitious in building its own physical infrastructure.

The process of deciding interconnection charges based on LRAIC is a long and complicated process, and NTA commissioned a consortium headed by Andersen Management International (AMI) and with the participation of European Economists and Center for Tele-Information to facilitate the process. The process adopted in Denmark resembles what followed in other EU countries like the UK and Austria (Freund \& Ruhle, 2002). The process comprises five stages: setting the rules, modeling, comparison, hybrid modeling and, finally, price determination.

The rules were set according to three model reference papers prepared by the AMI consortium and revised, following the comments from the three parties. This work was completed in late 2000. Thereafter TDC was responsible for preparing a Top-down model based on the existing network, while the Bottom-up Working Group was responsible for the preparation of a bottom-up model of a network building on the current physical network structure, but optimized with respect to technology and configuration (the scorched network approach). This work was completed in late 2001, and the two models have been compared, so a hybrid model based on results from the top-down and bottom-up models could be made.

The exact figures derived from the two cost models are not publicly available, but the reconciliation report indicates that the top-down model ends up with networking costs that are about twice the costs that can be derived from the bottom-up model. The two models 
are quite different in their network architecture, but it seems that the main differences originate from different assumptions in following areas:

(1) Annualisation rates - mainly due to different assumptions in price trends and costs of capital.

(2) Indirect costs, operating costs and overheads.

(3) Trench lengths and trench sharing with other utilities.

(4) Routing tables and network dimensioning including dimensioning of exchanges.

(5) Utilization rates.

The impact of each set of assumptions is analysed by including the assumptions from the top-down model in the bottom-up model.

Having analyzed the impact of the various assumptions, it is now the task of NTA to assess the appropriateness of these and to decide on the assumptions that should be made in the subsequent hybrid modeling.

\section{The impact on competition on the Danish market}

Early liberalisation and low interconnection rates seem to have attracted foreign telecom operators to the Danish market. Although the incumbent operator TDC still dominates the Danish market, some competition has developed since the telecom market was fully liberalised in 1997. TDC is by far the major provider of infrastructure in particular in the access network, but some infrastructure competition has developed at the inter-exchange and international markets (NTA, 2001). Nonetheless regulation is still considered to be necessary to ensure network access to new operators and promote competition in the telecom service market. The market shares of TDC on markets for end user services are depicted in Figure 2.

Competition is most visible on the market for mobile communications. Four operators with their own networks compete on a market with 5.2 million inhabitants. The incumbent operator still dominates the market with a market share of $42 \%$, the three other operators, Sonofon, Orange and Telia hold market share of 24, 15 and 7\%, while a number of service providers share the remaining $13 \%$. Hutchinson won one of the four UMTS licenses put on auction last year and is expected to be the fifth mobile carrier with its own network.

Regulation of interconnection charges is crucial for competition in the market for mobile services. Although the dominating mobile operators have built their own network facilities, payment of interconnection charges for the new entrants constitutes as much as $30 \%$ or more of the total costs.

For the market in fixed services there is some competition on traffic - in particular international traffic, while TDC still dominates the access markets for both telephony and ADSL.

The figures indicate that five years after the Danish telecom market was liberalised and cost based interconnection rates introduced, some competition has developed in most markets. On the other hand, there is no indication of a slow down in investments caused by 
low rates for interconnection services. In the same period of time, there has been considerable growth in telecom investments not only by the new entrants but also by TDC.

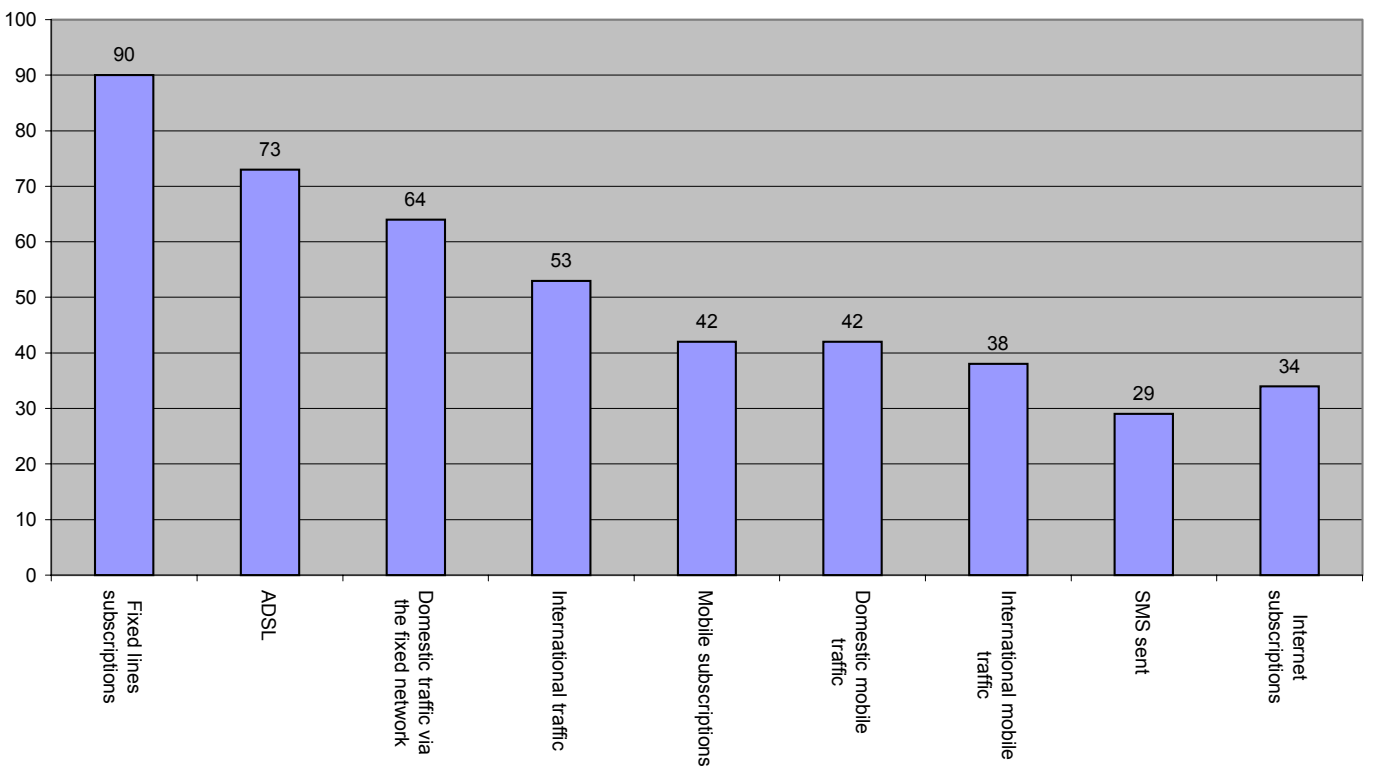

Source: National Telecom Agency: Telecom Statistics - Second half of 2001.

\section{Figure 2: TDC market shares 2H2001}

The exception is fixed local loop services. Although TDC has been forced to provide unbundled local loop services TDC still holds $90 \%$ of the fixed line subscription and also provides $73 \%$ of the ADSL lines. It may be too early to evaluate how the regulation of unbundling will impact the market. TDC has lost a market share of $10 \%$ of the fixed lines subscriptions in two years. But the market for ADSL shows the opposite trend. Here TDC has been able to increase its market share from 37 to $73 \%$ from 2000 to 2001 . This could indicate that current legislation is insufficient to ensure real competition on this market.

\section{Conclusion}

Determination of interconnection charges is both a political and a technical issue. It is not possible to define completely objective criteria which can be used to set the 'correct' charges. The purpose of regulation of interconnection prices is to promote service based competition by ensuring new entrants' access to existing network facilities on conditions that enable them to compete with existing operators. On the other hand interconnection rates must not be so low that they discourage investments in new network facilities and delay facility based competition. It is in order to maintain this delicate balance that the concept of LRAIC based interconnection charges has been developed. The question is whether use of LRAIC will induce competition. 
The experience from the Danish market indicates that low interconnection rates induce competition in most segments. But the local loop is an important exception from this. One reason may be that the history of local loop unbundling is relatively short, but the development in the market for ADSL indicates that there might be other reasons as well.

In Denmark low interconnection charges was not ensured by use of TELRIC or LRAIC. Initially interconnection charges were based on historical cost accounting. When it appeared that the outcome of this method resulted in prices, which were considered to be too high to promote real competition and to ensure Denmark a place among the countries with the lowest interconnection charges, this method was supplemented with a best practice clause.

Use of the best practice principle has insured Denmark a position among the countries offering the lowest interconnect rates in Europe. The LRAIC approach does not include such a guaranty. On the other hand it will be difficult to justify use of the best practice principle as more than a temporary solution - in particular if use of an LRAIC model can document costs that are either above or below the level given by best practice.

The outcome of charges determined by use of LRAIC will properly result in prices lower than the historic costs, but it is an open question whether the charges will be lower than the current charges. This will depend on the assumptions used. Even though LRAIC modeling is a technically complicated process, there will still be a discretionary element in the price setting.

Low interconnection prices induce competition. But it is too early to conclude whether LRAIC always will result in prices that are low enough to fulfill this objective. This depends on how LRAIC is implemented. There are examples from other countries, where interconnect prices set by use of LRAIC were higher than the actual end user prices. In Denmark the costs derived from the bottom-up model are only half of those derived from the top-down model. Therefore much depends on how the reconciliation is implemented.

It is still too early to draw firm conclusions on the market for local loop services, but here it might be necessary to take additional measures in order to establish real competition.

The LRAIC model provides a framework for rate-setting, in which it is possible to involve all operators, as they can be asked to prepare their own models and to comment on decisions taken in each phase of the process. Although it is difficult to imagine that operators will agree on all decisions taken, the modeling will contribute to more consensus on interconnection charges, both with regard to methodologies used and with regard to the level of charges. Thereby LRAIC will define a level playing field accepted by all parties.

The LRAIC modeling has been a long and complicated process. Nonetheless the implementation has largely been on schedule, and considering the financial implications of interconnection charges for the telecom carriers the resources spent have been limited, and there is no reason to see it as an unreasonably complicated process.

\section{$7 \quad$ References}

Commission of the European Communities (1997) "Directive 97/33/EC of the European Parliament and of the Council of 30 June 1997 on Interconnection in Telecommunications 
with regard to ensuring universal service and interoperability through application of the principles of Open Network Provision", (ONP) (OJ L199/32, 26.07.97).

Commission of the European Communities (1998) "Recommendation 98/511/EC of 29 July 1998 on Interconnection in a liberalised telecommunications market (Part 1 Interconnection Pricing)."

Commission of the European Communities (2000) "Amendment of 20.03.2000 to Recommendation 98/511/EC of 29 July 1998 on Interconnection in a liberalised telecommunications market (Part 1 - Interconnection Pricing).”

FindLaw (2002): "Verizon Communications Inc. etal. V. Federal Communications Commission etal". http://aws.findlaw.com/us/000/00-511.html.

Freund, Natascha \& Ernst-Olav Ruhle (2002) "Regulatory concepts for fixed-to-fixed and fixed-to-mobile interconnection rates in the European Union", The 17th European Communications Policy Research Conference, Barcelona 2002.

Intven, Hank (ed.) (2000) “Telecommunications Regulation Handbook", World Bank, Washington DC 2000.

National Telecom Agency (2001) "Analysis of competition on wholesale markets for telecom services", Copenhagen (in Danish).

National Telecom Agency (2002) "Status 2001", Copenhagen. http://www2.tst.dk/uk/publications/beret2001_eng/index.htm

National Telecom Agency (2002) "Telecom Statistics - Second half of 2001", Copenhagen. http://www.itst.dk/wimpblob.asp?objno=97331904

National Telecom Agency (2002) "Common Guidelines for the Top-Down and Bottom-up Cost Analysis".

National Telecom Agency (2002) "Reconciliation Report - Differences between the topdown and bottom-up cost analyses", Copenhagen, March. http://www.itst.dk/wimpdoc.asp?page=tema\&objno=95026348\#spe-mod 